\title{
The Dependence of GaN HEMT's Frequency Figure of Merit on Temperature
}

\author{
Ali M. Darwish, Benjamin Huebschman, Edward Viveiros, and H. Alfred Hung \\ Army Research Laboratory, 2800 Powder Mill Rd., Adelphi, MD 20783
}

\begin{abstract}
This study presents extensive thermal characterization of $\mathrm{GaN} / \mathrm{SiC}$ devices from five US sources across temperature $\left(-25^{\circ} \mathrm{C}\right.$ to $\left.+125^{\circ} \mathrm{C}\right)$. The changes with temperature for: cutoff frequency $\left(f_{t}\right)$, maximum oscillation frequency $\left(f_{\max }\right)$, saturated current $\left(I_{d s s}\right)$, transconductance $\left(g_{m}\right)$ are measured, statistics studied, and correlations investigated. Temperaturecoefficients are established for $f_{\mathrm{t}}, f_{\text {max }}, I_{\mathrm{dss}}$, and $g_{\mathrm{m}}$ in GaN technology. The results obtained provide MMIC designers with key information required for meeting temperature specifications.
\end{abstract}

Index Terms - Gallium nitride, temperature coefficient, cutoff frequency, maximum oscillation frequency, saturated current, transconductance, MMIC.

\section{INTRODUCTION}

Wide bandgap GaN devices show much higher power densities and potential for higher temperature operation than GaAs, Si, and SiGe devices [1]-[2]. The reliability and performance of HEMTs and MMICs depend critically on the device's operating channel temperature [3]. This study presents extensive characterization and comparison of $\mathrm{GaN} / \mathrm{SiC}$ devices from five sources (foundries / research and development labs) across temperature $\left(-25\right.$ to $\left.+125^{\circ} \mathrm{C}\right)$.

Modern modulation techniques combine several challenging requirements together such as linearity, and high peak-toaverage ratios (up to $12 \mathrm{~dB}$ for 128-QPSK), also known as the crest factor. In addition to electrical nonlinearities that are exacerbated by the crest factor, thermal dependencies of the device add to the gain, and phase nonlinearity as the device's performance varies with changes in the signal envelope. Understanding the dependence of key transistor parameters (such as $f_{\mathrm{t}}, f_{\mathrm{max}}, g_{m}$, and $I_{d s s}$ ) on temperature is critical for designing MMICs that work reliably over a wide temperature range.

Measuring device temperature dependencies from a single source is useful and informative. However, when assessing the potential of a technology (e.g. $\mathrm{Si}, \mathrm{GaAs}$, or $\mathrm{GaN}$ ), it is important to examine data from many sources so that a technology baseline can be established. In this study, the data from five US sources are collected and presented. For each vendor, two similar size devices were measured. This study expands on our previous work [4] by investigating the dependence of the HEMT's frequency figure of merit $f_{\mathrm{t}}$, and $f_{\text {max }}$ on temperature. In addition, frequency dependencies are compared with those of saturated current $\left(I_{\mathrm{dss}}\right)$, and transconductance $\left(g_{\mathrm{m}}\right)$ and conclusions are drawn. One unexpected observation is that the temperature-coefficients (TC) for $f_{\mathrm{t}}$, and $f_{\max }$ are not correlated. Thus, having a large $\mathrm{TC}\left(f_{\mathrm{t}}\right)$ does not necessarily indicate that $\mathrm{TC}\left(f_{\max }\right)$ will be significant. In fact, the two may be opposite.

\section{MEASURED RESULTS}

To quantize the effect of temperature on the performance of GaN/SiC devices, a set of AlGaN/GaN HEMTs were characterized at $-25,25,75$, and $125^{\circ} \mathrm{C}$ base plate temperature of the on-wafer device characterization system. At each temperature, the DC IV curves were measured and $I_{d s s}$ recorded. In addition, the on-wafer S-parameters were measured at $\mathrm{V}_{\mathrm{d}}=20 \mathrm{~V}$ and a fixed drain current (equal to $50 \%$ of the room-temperature $\mathrm{I}_{\mathrm{dss}}$ ). The dissipated DC power is fixed and hence the channel temperature to the chuck temperature should be constant (assuming $\mathrm{GaN}$ and $\mathrm{SiC}$ have linear thermal conductivities over the -25 to $+125^{\circ} \mathrm{C}$ temperature range). The gate lengths $\left(L_{\mathrm{g}}\right)$ for the HEMTs were between $0.2-0.4 \mu \mathrm{m}$. Two important technology/device metrics are the cutoff frequency $\left(f_{\mathrm{t}}\right)$, and maximum oscillation frequency $\left(f_{\max }\right)$. The cutoff frequency $\left(f_{\mathrm{t}}\right)$, is defined as the frequency at which the current gain $\left(h_{21}\right)$ equals unity, and maximum oscillation frequency $\left(f_{\max }\right)$ is defined as the frequency at which Mason's maximum unilateral power gain (U) equals unity [5]. Above $f_{\max }$, one can consider the HEMT as a passive component.

Clearly high $f_{\mathrm{t}}$, and $f_{\max }$, are correlated with short gate length devices. To facilitate the discussion, consider the simplified equivalent circuit for a HEMT show in Fig. 1.

The following relations can be derived:

$$
\begin{aligned}
& I_{o}=g_{m} V_{g s} \\
& V_{g s}=\frac{I_{i n}}{j \omega C_{g s}} \\
& h_{21}=\frac{I_{o}}{I_{i n}}=\frac{g_{m} V_{g s}}{I_{i n}}=\frac{g_{m}}{j \omega C_{g s}}
\end{aligned}
$$

Given that $\left|h_{21}\right|=1$ at $f_{\mathrm{t}}$, one may calculate,

$$
f_{t}=\frac{g_{m}}{2 \pi C_{g s}}
$$

For the simplified equivalent circuit in Fig. 1, one may also find that for $f_{\max }[6]$, 


$$
f_{\max } \propto \frac{f_{t}}{2} \cdot \sqrt{\frac{R_{o}}{R_{i n}}}
$$

where $R_{\text {in }}$ is the sum of all input resistances. One important difference between $f_{\mathrm{t}}$, and $f_{\text {max }}$, is that $f_{\mathrm{t}}$ is not affected by input and output parasitics [6]-[7], while $f_{\max }$ is affected.

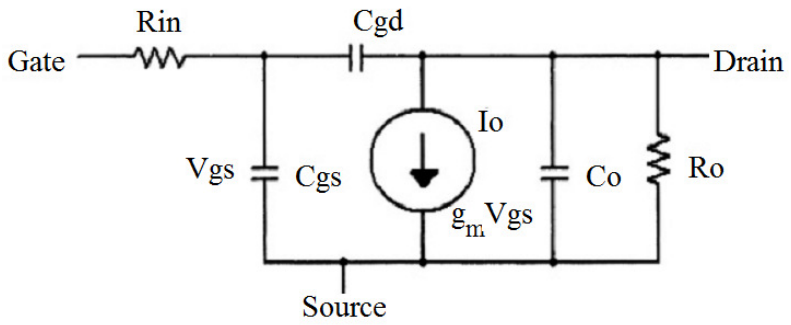

Fig. 1. Equivalent circuit for HEMT.

In all the results below, $f_{\mathrm{t}}$, and $f_{\max }$ are calculated from measured S-parameters directly without any fitting to an equivalent circuit. The measured temperature variation of $f_{\mathrm{t}}$, and $f_{\max }$ is presented in Figs. $2 \mathrm{a}$, and $2 \mathrm{~b}$, respectively. A sample plot of $h_{21}$ data for one of the devices is shown in Fig. $3 \mathrm{a}$. One may extract $f_{\mathrm{t}}$ values from the $x$-axis intercept. Similarly, $f_{\max }$ can be extracted from the $x$-axis intercept of the maximum unilateral power gain $\mathrm{dB}(\mathrm{U})$. However, a more stable and accurate value for $f_{\mathrm{t}}$, and $f_{\max }$ can be found by extending a $20 \mathrm{~dB} /$ decade line from each data point and equating the $x$-axis intercept to $f_{\mathrm{t}}$ (for $h_{21}$ curve), and $f_{\max }$ (for $\mathrm{U}$ curve). This is what was used here in finding $f_{\mathrm{t}}$, and $f_{\max }$. Thus, for every device, at each temperature, and at each frequency, a $f_{\mathrm{t}}$, and $f_{\max }$ are extracted (Fig. $3 \mathrm{~b}$ shows an example) and then the $f_{\mathrm{t}}$, and $f_{\max }$ values are averaged and used in our analysis. This approach ensures that our $f_{\mathrm{t}}$, and $f_{\max }$ result is not sensitive to measurement noise or to a particular irregularity at a frequency point. Instead, all the data points contribute to the value of $f_{\mathrm{t}}$, and $f_{\max }$.

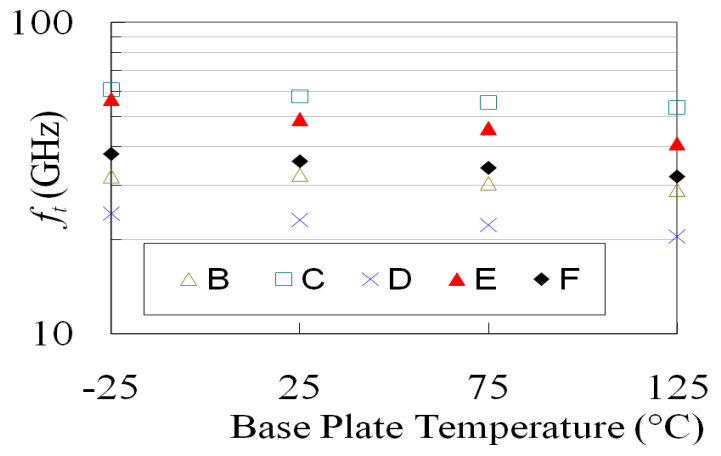

Fig. 2a, the cutoff frequency $f_{\mathrm{t}}$ of the different devices measured across temperature.

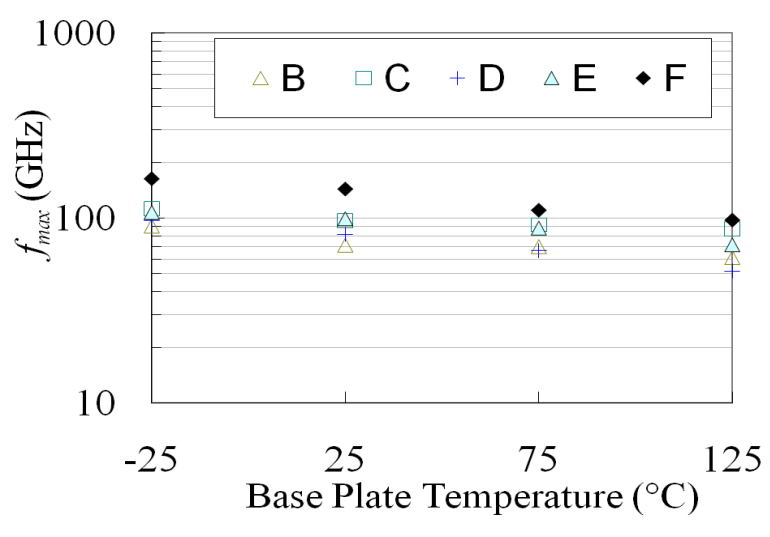

Fig. $2 \mathrm{~b}$, the maximum frequency of oscillation $f_{\max }$ of the different devices measured across temperature.

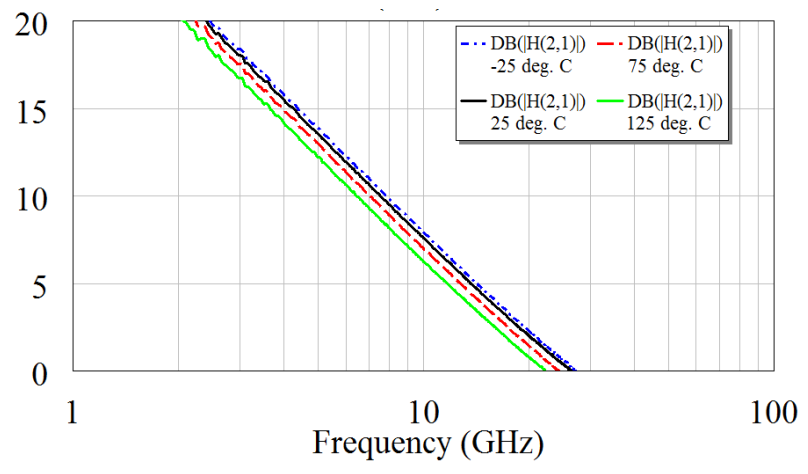

Fig. 3a. Plot of current gain as a function of frequency. The $\mathrm{x}-$ intercept happens at $f_{\mathrm{t}}$.

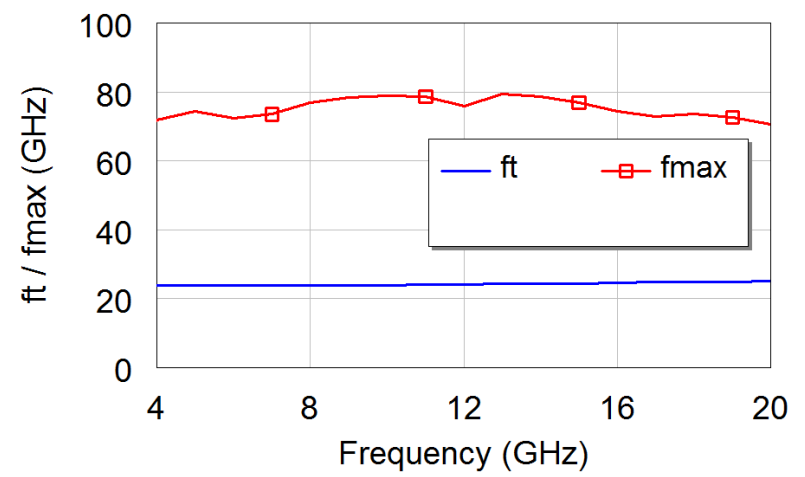

Fig. 3b. Plot of extracted $f_{\mathrm{t}}$, and $f_{\max }$ as a function of frequency.

The change with temperature may be measured by defining a temperature coefficient as $\operatorname{TC}(x)=\left(\Delta x / x_{o}\right) / \Delta T$, where $x_{o}$ is the value of the parameter (e.g. $f_{\mathrm{t}}, f_{\max }, g_{m}$, or $I_{d s s}$ ) of interest at $25^{\circ} \mathrm{C}$. The TC for $f_{\mathrm{t}}$, and $f_{\max }$ are shown in Fig. 4 . The ratio of $\operatorname{TC}\left(f_{\max }\right) / \operatorname{TC}\left(f_{t}\right)$ for the five samples of devices are presented in Table I. 


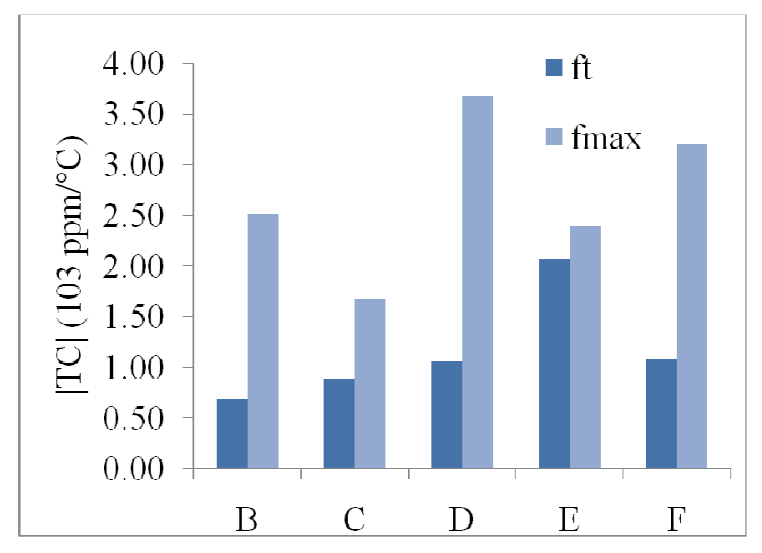

Fig. 4. The temperature coefficient of $f_{\mathrm{t}}$, and $f_{\max }$.

TABLE I

THE TEMPERATURE COEFFICIENTS OF $f_{\mathrm{t}}$, AND $f_{\max }$

\begin{tabular}{|cccc|}
\hline Device & $T C\left(f_{t}\right)$ & $T C\left(f_{\max }\right)$ & $\frac{T C\left(f_{\max }\right)}{T C\left(f_{t}\right)}$ \\
B & -0.70 & -2.51 & 3.60 \\
C & -0.88 & -1.67 & 1.89 \\
D & -1.06 & -3.67 & 3.47 \\
E & -2.08 & -2.39 & 1.15 \\
F & -1.09 & -3.21 & 2.96 \\
\hline
\end{tabular}

\section{DISCUSSION AND ANALYSIS}

One immediate observation from table I is that the TCs are not correlated. For example device B has higher TC $\left(f_{\max }\right)$ than device $\mathrm{C}$ while having a lower $\mathrm{TC}\left(f_{\mathrm{t}}\right)$ than $\mathrm{C}$. The same goes for devices $\mathrm{B}$, and $\mathrm{E}$. This is somewhat unexpected since according to equation (2), $f_{\max }$ is proportional to $f_{\mathrm{t}}$ and one may expect $d f_{\text {max }} / d T$ to be proportional to $d f_{\mathrm{t}} / d T$. The parasitics are clearly playing a large role and one cannot easily predict $\mathrm{TC}\left(f_{\max }\right)$ from TC $\left(f_{\mathrm{t}}\right)$.

Another observation is that $\mathrm{TC}\left(f_{\max }\right)$ is consistently larger than $\mathrm{TC}\left(f_{\mathrm{t}}\right)$. This points to the fact that the parasitics exacerbate the degradation of $f_{\max }$ with temperature and do not help, in general. It is interesting to note the differences between $\mathrm{TC}\left(f_{\mathrm{t}}\right)$ and $\mathrm{TC}\left(f_{\max }\right)$. In one case (device $\left.\mathrm{E}\right) \mathrm{TC}\left(f_{\mathrm{t}}\right)$ and $\mathrm{TC}\left(f_{\max }\right)$ are almost equal while in another case (device $\mathrm{D})$, TC $\left(f_{\max }\right)$ is more than three times larger than TC $\left(f_{\mathrm{t}}\right)$.

For comparison purposes, Table II presents TC $\left(f_{\mathrm{t}}\right), \mathrm{TC}\left(f_{\max }\right)$, $\mathrm{TC}\left(g_{\mathrm{m}}\right)$, and $\mathrm{TC}\left(I_{\mathrm{dss}}\right)$, and Fig. 5 shows a plot of the data. Clearly there is some correlation between $f_{\mathrm{t}}$, and $g_{m}$, and $I_{d s s}$. To explore this relation further, the correlation between the different quantities is calculated and shown in Table III. The correlation was computed using Microsoft Excel's "CORREL" function.

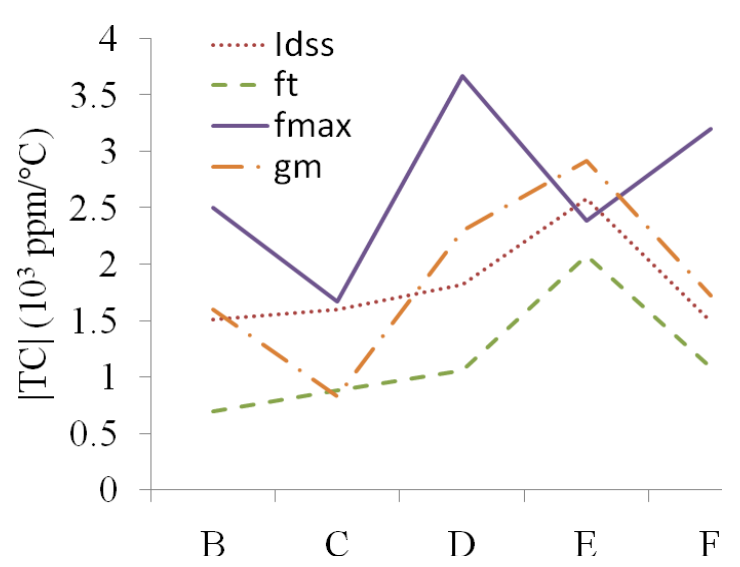

Fig. 5. The temperature coefficient of $f_{\mathrm{t}}, f_{\max }, g_{m}$, and $I_{d s s}$.

TABLE II

THE TEMPERATURE COEFFICIENTS OF $f_{\mathrm{t}}, f_{\max }, g_{m}$, AND $I_{d s s}$

\begin{tabular}{|ccccc|}
\hline Device & $T C\left(f_{t}\right)$ & $T C\left(f_{\max }\right)$ & $T C\left(g_{m}\right)$ & $T C\left(I_{d s s}\right)$ \\
B & -0.70 & -2.51 & -1.61 & -1.52 \\
C & -0.88 & -1.67 & -0.83 & -1.61 \\
D & -1.06 & -3.67 & -2.30 & -1.82 \\
E & -2.08 & -2.39 & -2.92 & -2.59 \\
F & -1.09 & -3.21 & -1.72 & -1.50 \\
\hline
\end{tabular}

TABLE III

CORRELATION BETWEEN $f_{\mathrm{t}}, f_{\max }, g_{m}$, AND $I_{d s s}$

\begin{tabular}{|ccc|}
\hline \multicolumn{3}{|c|}{ Correlation } \\
$f_{t}$ & $f_{\text {max }}$ & -0.03 \\
$f_{t}$ & $g_{m}$ & 0.80 \\
$f_{t}$ & $I_{d s s}$ & 0.95 \\
$f_{\text {max }}$ & $g_{m}$ & 0.47 \\
$f_{\text {max }}$ & $I_{d s s}$ & -0.08 \\
$g_{m}$ & $I_{d s s}$ & 0.81 \\
\hline
\end{tabular}

Note that, in terms of temperature coefficients, $f_{\mathrm{t}}$ and $f_{\max }$ are not correlated as observed earlier, while $f_{\mathrm{t}}$ and $g_{m}$, and $I_{d s s}$ are positively correlated.

Table IV summarizes the statistics of each parameter. These values should be useful for MMIC design purposes.

Last, it is important to realize that in all of the measurements above, the base plate temperature was referenced, instead of the channel temperature. The assumption is that when the base plate temperature changes by $50^{\circ} \mathrm{C}$, say, then the channel temperature will change by $50^{\circ} \mathrm{C}$ too. This is a good assumption if the nonlinearity of the thermal conductivity is small. 


\section{CONCLUSION}

When considering the suitability of a process/technology, one first considers the figures of merit of the device $\left(f_{\mathrm{t}}, f_{\max }\right.$, $g_{m}, I_{d s s}$, etc.). For example, in designing a MMIC amplifier, it is common to choose a process where $f_{\max }$ is $2 \mathrm{x}$ or $3 \mathrm{x}$ larger than the highest operating frequency. What our study highlights is that one must consider the base plate temperature at the higher end of the specifications and reevaluate the process/technology. Thus, if the specifications call for operation at $125^{\circ} \mathrm{C}$, one can estimate that $f_{\max }$ will be reduced, on average (see Table IV), by $\mathrm{TC}\left(f_{\max }\right) \times \Delta$ Temperature $=2.69$ $\times 10^{-3} \times(125-25) \approx 0.27$ or $27 \%$, and under the worst case scenario, it could be reduced by $37 \%$ at $125^{\circ} \mathrm{C}$. Hence, an initially suitable process may no longer be suitable after the higher temperature end is considered.

Similar arguments can be extended for transconductance, $g_{m}$, power handling capability, and saturation current, $I_{d s s}$.

In summary, the temperature behavior of HEMT parameters were measured from five different US sources. The statistics were established for the temperature coefficients of $f_{\mathrm{t}}, f_{\max }, g_{m}$, and $I_{d s s}$. These coefficients are important for MMIC designers in estimating the design specifications over temperature.

\section{REFERENCES}

[1] T. Palacios, A. Chakraborty, S. Rajan, C. Poblenz, S. Keller, S.P. DenBaars, J. Speck, U. Mishra, "High-power AlGaN/GaN HEMTs for Ka-band applications," IEEE Electron Device Letters, volume 26, issue 11, pp. 781 - 783, 2005.

[2] Wu, Y.-F., Saxler, A., Moore, M., Smith, R.P., Sheppard, S., Chavarkar, P.M., Wisleder, T., Mishra, U.K., Parikh, P., "30W/mm GaN HEMTs by Field Plate Optimization," IEEE Electron Device Letters, vol. 25, pp. 117-119, 2004.

[3] A. Darwish, A. Bayba, H. A. Hung, "Thermal Resistance Calculation of AlGaN-GaN Devices," IEEE Trans. On Microwave Theory and Tech., vol. 52, no. 11, pp. 2611-2620, Nov. 2004. See also IEEE Trans. on Microwave Theory and Tech., vol. 53, issue 9, pp. 3051-3052, 2005.

[4] Ali M. Darwish, B. Huebschman, R. Del Rosario, E. Viverios, and H. A. Hung, "Temperature Behavior of AlGaN/GaN on SiC HEMTs," IEEE Compound Semiconductor IC Symp. 2005, Palm Springs, CA, Oct. 31- Nov. 2, IFTH-55, 2005.

[5] S. J. Mason, "Power gain in feedback amplifiers," IRE Trans. Circuit Theory, vol. CT-I, pp. 20-25, June 1954.

[6] G. Vendelin, A. Pavio, U. Rohde, Microwave Circuit Design Using Linear and Nonlinear Techniques, NY, John Wiley \& Sons, 1990; see also R. J. Trew, M. B. Steer and D. Chamberlain, "Parasitic effects upon the high-frequency performance of three-terminal devices," Proc. $3 \mathrm{rd} \mathrm{GaAs}$ Simulation Workshop, Duisburg, Germany, Oct. 7-8, 1986.

[7] J. Lange, "Microwave transistor characterization including Sparameters," HP Application Note 95, pp. 1-1 - 1-13, Sept. 1968.

TABLE IV

STATISTICS OF TEMPERATURE COEFFICIENT FOR ALL MEASURED DEVICES

\begin{tabular}{|c|c|c|c|c|c|}
\hline Temp. Coeff. & Units & Mean & Std Dev. & Min. & Max. \\
\hline$\Delta \mathrm{I}_{\mathrm{dss}} / \mathrm{I}_{\mathrm{dss}} \Delta \mathrm{T}$ & $10^{3} \mathrm{ppm} /{ }^{\circ} \mathrm{C}$ & -1.67 & 0.44 & -1.01 & -2.59 \\
\hline$\Delta \mathrm{g}_{\mathrm{m}} / \mathrm{g}_{\mathrm{m}} \Delta \mathrm{T}$ & $10^{3} \mathrm{ppm} /{ }^{\circ} \mathrm{C}$ & -1.87 & 0.80 & -0.83 & -2.92 \\
\hline$\Delta f_{\mathrm{t}} / f_{\mathrm{t}} \Delta \mathrm{T}$ & $10^{3} \mathrm{ppm} /{ }^{\circ} \mathrm{C}$ & -1.16 & 0.54 & -0.70 & -2.08 \\
\hline$\Delta f_{\max } / f_{\max } \Delta \mathrm{T}$ & $10^{3} \mathrm{ppm} /{ }^{\circ} \mathrm{C}$ & -2.69 & 0.77 & -1.67 & -3.67 \\
\hline
\end{tabular}

